\title{
A Randomized Study of Patients with Advanced Gastric Adenocarcinoma Not Progressed After Six Cycles of XELOX (Capecitabine Plus Oxaliplatin) Followed by Capecitabine Maintenance or Clinical Observation
}

\section{Guk Jin Lee}

Catholic University of Korea Bucheon Saint Mary's Hospital

Hyunho Kim

The Catholic University of Korea St Vincent's Hospital

\section{Sung Shim Cho}

The Catholic University of Korea St Vincent's Hospital

\section{Hyung Soon Park}

The Catholic University of Korea St Vincent's Hospital

\section{Ho Jung An}

The Catholic University of Korea St Vincent's Hospital

\section{In Sook Woo}

Catholic University of Korea Yeouido Saint Mary's Hospital

\section{Jae Ho Byun}

Incheon Seongmo Byeongwon: Catholic University of Korea Incheon Saint Mary's Hospital

\section{Ji Hyung Hong}

Catholic University of Korea Eunpyeong St Mary's Hospital

\section{Yoon Ho Ko}

Catholic University of Korea Eunpyeong St Mary's Hospital

\section{Der Sheng Sun}

Gatollik Daehakgyo Uijeongbu Seongmo Byeongwon: Uijeongbu Saint Mary's Hospital

\section{Hye Sung Won}

Gatollik Daehakgyo Uijeongbu Seongmo Byeongwon: Uijeongbu Saint Mary's Hospital

Jong Youl Jin

Catholic University of Korea, Bucheon St Mary hospital

\section{Ji Chan Park}

The Catholic University of Korea,Daejeon St.Mary hospital

\section{In-Ho Kim}

The Catholic University of Korea, Seoul St Mary hsopital

\section{Sang Young Roh}

Seoul Saint Mary's Hospital 
Byoung Yong Shim ( $\nabla$ shimby@catholic.ac.kr)

The Catholic University of Korea St Vincent's Hospital https://orcid.org/0000-0001-6473-786X

\section{Research Article}

Keywords: Stomach neoplasm, Capecitabine, Maintenance chemotherapy, Clinical trial

Posted Date: February 24th, 2022

DOI: https://doi.org/10.21203/rs.3.rs-1076759/v1

License: (c) (i) This work is licensed under a Creative Commons Attribution 4.0 International License. Read Full License 


\section{Abstract \\ Background}

Oxaliplatin as part of XELOX regimen has a more favorable toxicity profile than cisplatin for patients with advanced gastric cancer (GC). However, oxaliplatin can induce sensory neuropathy, a cumulative, dose-related toxicity. Thus, capecitabine maintenance regimen might achieve maximum treatment effect while reducing cumulative neurotoxicity of oxaliplatin. The aim of this study was to compare survivals of AGC patients between capecitabine maintenance and observation after 1st line XELOX chemotherapy.

\section{Methods}

Sixty-three patients treated with six cycles of XELOX for AGC in six hospitals of the Catholic University of Korea were randomized 1:1 to capecitabine maintenance or observation. The primary end point was PFS (PFS) analyzed using a two-sided log-rank test stratified at $5 \%$ significance level.

\section{Results}

Between 2015 and 2020, 32 and 31 patients were randomized to maintenance and observation groups, respectively. After randomization, the median number of cycles for maintenance capecitabine was 6 . PFS was significantly higher for the maintenance group (6.3 months vs. 4.1 months, $P=0.010$ ). OS (OS) was not significantly different between the two groups (18.2 months vs. 16.5 months, $P=0.624$ ). Toxicity such as hand-foot syndrome was reported in some cases of the maintenance group. Maintenance treatment was a significant factor associated with PFS in multivariate analysis (HR: $0.472,95 \% \mathrm{Cl}: 0.250-0.890, P=0.020$ ).

\section{Conclusions}

After six cycles of XELOX chemotherapy, capecitabine maintenance significantly prolonged PFS than observation and toxicity was manageable. Maintenance treatment was a significant prognostic factor associated with PFS.

\section{Introduction}

The prognosis of metastatic gastric cancer (GC) is still poor, showing a great unmet need [1, 2]. So far, the 1st line standard treatment of advanced HER2-negatvie GC is systemic chemotherapy of platinum/fluoropyrimidine [3]. In most patients, chemotherapy is difficult to administer more than 6-8 cycles due to cumulative side effects and reduced performance status. In addition, second-line treatment is less effective than first-line treatment and is more difficult to withstand side effects, so about $20-40 \%$ of patients diagnosed with advanced GC can receive second line therapy [4].

It is clinically critical to consolidate the effectiveness of first-line treatment and delay tumor progression. Maintenance therapy is a very important issue in oncology recently. It is mainly used in colorectal cancers 
(CRCs) and non-small-cell lung cancer (NSCLCs) [5]. Candidate agents for maintenance therapy in NSCLCs include agents used in the first-line chemotherapy and new cytotoxic agents with fewer toxicity than first-line chemotherapeutic agent or target agents [6].

There is no definite recommendation of maintenance chemotherapy for metastatic HER2-negative GC on current clinical guidelines such as national comprehensive cancer network (NCCN) guideline and European Society for Medical Oncology (ESMO) guideline [7, 8]. However, many retrospective and observational studies have shown the efficacy and safety of maintenance fluoropyrimidine treatment compared with observation alone $[7,8]$.

Park et al. [9] have observed that oxaliplatin as part of XELOX (Capecitabine plus Oxaliplatin) regimen has a more favorable toxicity profile than cisplatin for patients with advanced GC (AGC). However, oxaliplatin can induce sensory neuropathy, a cumulative, dose-related toxicity. Therefore, it might be possible to devise a capecitabine maintenance regimen to achieve the maximum treatment effect before cumulative neurotoxicity appears. The objective of this study was to report results of a randomized phase III study of patients with advanced gastric adenocarcinoma not progressed after six cycles of XELOX followed by capecitabine maintenance or clinical observation.

\section{Materials And Methods}

\section{Inclusion and exclusion criteria}

Inclusion criteria were: 1) patients with histologically proven GC, Stage IV (regardless of the presence or absence of measurable disease by RECIST criteria) or recurrent after curative surgery and more than stable disease (SD) following six 6 cycles of 1 st line XELOX chemotherapy; 2) minimum age of 18 years; 3) negative expression $(0,1)$ of Her2 IHC or negative amplification of FISH in Her2 IHC $2+; 4)$ Eastern Cooperative Oncology Group Performance status 0-2, and 5) adequate bone marrow, renal, and hepatic functions. Exclusion criteria were: 1) patients who were previously exposed to any chemotherapy except XELOX for advanced disease, 2) those who received R0 or R1 resection for metastatic or recurrent GC without evaluable/measurable disease; 3 ) those who had disease relapsed during or within 4 months after adjuvant therapy; 4) those who had central nervous system and meningeal metastases ; 5) those who had significant neurologic or psychiatric disorders, 6) those with active infection, severe heart disease, uncontrollable hypertension or diabetes mellitus, myocardial infarction during the preceding 6 months, pregnancy, or breast feeding. Any previous or concurrent malignancy was not included except for adequately treated nonmelanoma skin cancer, in situ cancer of uterine cervix, non-muscle invasive bladder cancer, or malignancy without evidence of recurrence within five years.

\section{Study Design And Treatment}

This study was a multicenter randomized controlled phase III open label trial. Study subjects were randomized to two groups at a ratio of 1:1 and stratified by the presence of measurable lesion and tumor response to the initial six cycles of XELOX chemotherapy (Partial response (PR)/Complete response (CR) vs. 
SD/Non-CR, Non-Progressive disease (PD)). Group A, the maintenance group, was treated with Capecitabine $1000 \mathrm{mg} / \mathrm{m}^{2}$ bid D1-14 every 3 weeks until disease progression or unacceptable toxicity happened. Group B, the control group, was observed. The primary objective of this study was to compare progression free survival (PFS) between the two groups. We predicted that the median number of cycles for the maintenance group after randomization was up to 8 and the median follow-up period of patients after progression was up to 5 months.

\section{Assessments}

A response was evaluated radiologically every two cycles until 18 weeks and then every 3 cycles thereafter, or when progression was suspicious by RECIST criteria version 1.1. Overall response rate (ORR) was defined as the proportion of patients whose best response was either PR or CR. Disease control rate was defined as the proportion of patients whose best response was CR, PR, or SD. Safety was evaluated after every treatment by $\mathrm{NCl}$-CTCAE version 4.0. Primary endpoint was PFS. Secondary endpoints were Overall survival (OS), ORR, toxicity profile of chemotherapy, and quality of life.

\section{Statistical analysis}

We anticipated that the differential PFS between maintenance group and observation group is three months. The type 1 error probability associated with testing this null hypothesis was 0.05 and the test power was $80 \%$. Assuming approximately monthly $2 \%$ subjects drop out, the required number of each group is 40 and total patient accrual of 80 was warranted.

This study was designed to provide evidence to either support the null hypothesis $\mathrm{HO}: \lambda=1$ or to reject it in favor of the alternative hypothesis $\mathrm{HA}: \lambda \neq 1$, where $\lambda$ was the hazard ratio (HR) of PFS: experimental arm/control arm. Additionally, this study was designed to provide evidence to the similar hypothesis for OS, although OS was not the primary endpoint. All analyses were conducted using a 2-sided log-rank test stratified at an overall significance level of $5 \%$.

Relative dose intensity was defined as the actual dose divided by the standard dose. PFS was defined as the time from the date of randomization until the earliest date of disease progression or death due to any cause before documentation of progression. For subjects who had withdrawn from study treatment, tumor assessments should be followed afterwards in order to capture the date of disease progression appropriately. These patients should not be treated as censored due to discontinuation. PFS was summarized using KaplanMeier curves and compared between the two arms using a stratified log-rank test. OS was defined as the time from the date of randomization until death due to any cause. The same statistical methods were for analysis of OS and PFS. Univariate and multivariate analyses for PFS were performed using the Cox proportional hazard model to analyze independent prognostic factors. Analysis was performed using the SPSS 20.0 software package (IBM Corp., Armonk, NY, USA).

\section{Results}




\section{Patient characteristics}

Between 2015 and 2020, patients were enrolled from six hospitals of the Catholic University of Korea. Patient registration for this study has been delayed than expected. Based on the recommendation of Data Safety Monitoring Committee, we decided to analyze the interim results to check the current situation and determine the future direction. Overall, 64 patients were treated per protocol and each 32 and 31 patients were randomized to the maintenance group and the observation group, respectively (Fig. 1). One patient in observation group did not receive allocated intervention because of recent myocardial infarction which was considered a study violation.

Poor differentiation of the tissue was noticeably more frequent in the maintenance group than in the observation group $(P=0.013)$. Other clinical characteristics were similar between the two groups. There was no statistical difference between two groups in whether subsequent chemotherapy was performed $(P=0.890)$ (Table 1). 
Table 1

Clinical characteristics of subjects in the maintenance group or the observation group

\begin{tabular}{|c|c|c|c|}
\hline & $\begin{array}{l}\text { Maintenance group ( } n= \\
\text { 32) }\end{array}$ & $\begin{array}{l}\text { Observation group }(n= \\
\text { 31) }\end{array}$ & $\begin{array}{l}P \\
\text { value }\end{array}$ \\
\hline & $N(\%)$ & $N(\%)$ & \\
\hline Age (median, range) & $64.5,41-81$ & $61,40-79$ & 0.674 \\
\hline Age $<60$ & $13(40.6)$ & $11(35.5)$ & \\
\hline Age $\geq 60$ & $19(59.4)$ & $20(64.5)$ & \\
\hline Underlying disease & & & 0.059 \\
\hline No & $12(37.5)$ & $19(61.3)$ & \\
\hline Yes & $20(62.5)$ & $12(38.7)$ & \\
\hline Smoking history & & & 0.982 \\
\hline Never or Ex-smoker & $31(96.9)$ & $30(96.8)$ & \\
\hline Current & $1(3.1)$ & $1(3.2)$ & \\
\hline ECOG performance status & & & 0.238 \\
\hline $0-1$ & $31(96.9)$ & $31(100)$ & \\
\hline$\geq 2$ & $1(3.1)$ & $0(0)$ & \\
\hline Serum CEA (ng/ml) & & & 0.916 \\
\hline$<7.5$ & $20(62.5)$ & $20(64.5)$ & \\
\hline$\geq 7.5$ & $6(18.8)$ & $4(12.9)$ & \\
\hline Unknown & $6(18.8)$ & $7(22.6)$ & \\
\hline Histology subtype & & & 0.013 \\
\hline Well to Moderate & $3(9.4)$ & $11(35.5)$ & \\
\hline Poor & $29(90.6)$ & $20(64.5)$ & \\
\hline Disease status & & & 0.476 \\
\hline Initial metastasis & $20(62.5)$ & $22(71.0)$ & \\
\hline Recurrence & $12(37.5)$ & $9(29.0)$ & \\
\hline $\begin{array}{l}\text { Previous } \\
\text { adjuvant chemotherapy }\end{array}$ & & & 0.414 \\
\hline No & 23 (71.9) & 25 (80.6) & \\
\hline
\end{tabular}




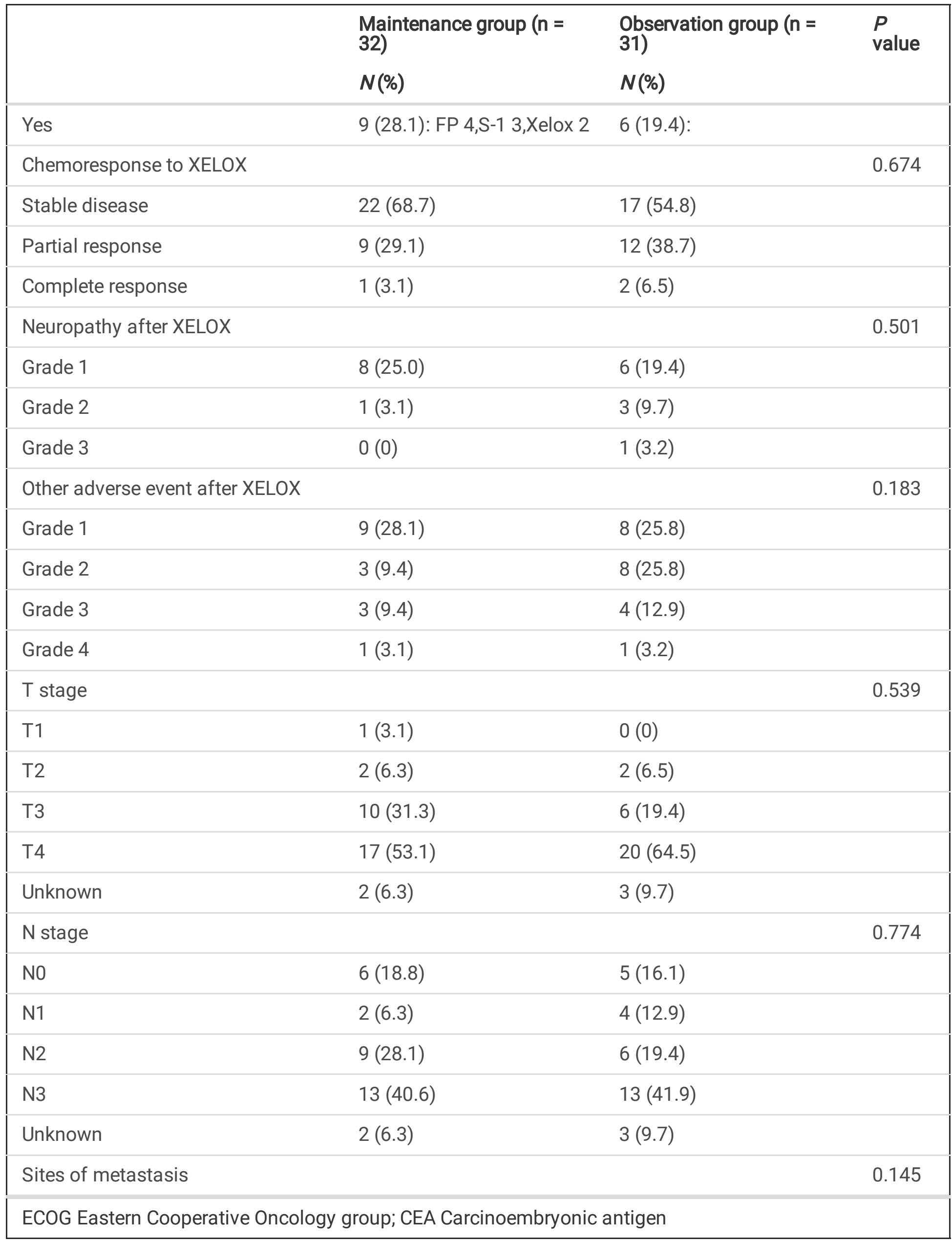




\begin{tabular}{|llll|}
\hline & Maintenance group $(\mathbf{n}=$ & Observation group $(\mathrm{n}=$ & $\boldsymbol{P}$ \\
& $\mathbf{3 2})$ & $\mathbf{3 1})$ & \\
\hline 1 & $\mathbf{N}(\%)$ & $\mathbf{N}(\%)$ & \\
\hline$\geq 2$ & $17(53.1)$ & $22(71.0)$ & \\
\hline Liver metastasis & $15(46.9)$ & $9(29.0)$ & 0.946 \\
\hline Peritoneal metastasis & $7(21.9)$ & $7(22.6)$ & 0.926 \\
\hline Lung metastasis & $21(65.6)$ & $20(64.5)$ & 0.247 \\
\hline $\begin{array}{l}\text { Non-regional lymph node } \\
\text { metastasis }\end{array}$ & $5(15.6)$ & $2(6.5)$ & 0.197 \\
\hline Bone metastasis & $12(37.5)$ & $7(22.6)$ & 0.426 \\
\hline Measurable lesion & $5(15.6)$ & $2(6.5)$ & 0.904 \\
\hline No & $17(53.1)$ & $16(51.6)$ & \\
\hline Yes & $15(46.9)$ & $15(48.4)$ & \\
\hline Subsequent chemotherapy & & $5(16.1)$ & \\
\hline No & $6(18.8)$ & $26(83.9)$ & \\
\hline Yes & $26(81.2)$ & & \\
\hline ECOG Eastern Cooperative Oncology group; CEA Carcinoembryonic antigen & \\
\hline
\end{tabular}

\section{Treatment Exposure}

The median number of cycles of capecitabine maintenance after randomization was 6 (range, 1-32). The median relative dose intensity (RDI) of capecitabine was 0.9 (range, 0.7-1).

\section{Efficacy}

PFS was significantly different between maintenance and control groups (median PFS: 6.3 months vs. 4.1 months, $P=0.010$ ) (Fig. 2). However, OS was not significantly different between the two groups (median OS: 18.2 months vs. 16.5 months, $P=0.624$ ) (Fig. 3 ).

\section{Safety}

Treatment-related adverse events (AEs) are summarized in Table 2. During previous XELOX chemotherapy, all grades of peripheral neuropathy were reported in 19 (30.2\%) patients. For more than grade 3 AEs, there were five $(7.9 \%)$ patients with neuropathy, three $(4.8 \%)$ patients with thrombocytopenia, two (3.2\%) patients with 
nausea, two (3.2\%) patients with vomiting, 1 (1.6\%) patient with asthenia, and $1(1.6 \%)$ patient with hand-foot syndrome (HFS). Of the maintenance group, all grades of HFS were found for $8(25 \%)$ patients. For more than grade $3 \mathrm{AEs}$, there were 4 (12.5\%) patients with grade $3 \mathrm{HFS}, 1$ (3.2\%) patient with grade 3 thrombocytopenia, and $1(3.2 \%)$ patient with grade 3 liver dysfunction in the maintenance group. One (3.2\%) patient with grade 3 asthenia was reported in the observation group. 
Table 2

Treatment-related adverse events in study patients $(n=63)$

\begin{tabular}{|c|c|c|c|c|c|c|c|c|c|}
\hline \multirow[t]{3}{*}{ Adverse event } & \multicolumn{3}{|c|}{ Previous XELOX ( $n=63)$} & \multicolumn{3}{|c|}{$\begin{array}{l}\text { Maintenance group }(n= \\
32)\end{array}$} & \multicolumn{3}{|c|}{$\begin{array}{l}\text { Observation group }(n= \\
31)\end{array}$} \\
\hline & $\begin{array}{l}\text { All } \\
\text { grades }\end{array}$ & $\begin{array}{l}\text { Grade } \\
3\end{array}$ & $\begin{array}{l}\text { Grade } \\
4\end{array}$ & $\begin{array}{l}\text { All } \\
\text { grades }\end{array}$ & $\begin{array}{l}\text { Grade } \\
3\end{array}$ & $\begin{array}{l}\text { Grade } \\
4\end{array}$ & $\begin{array}{l}\text { All } \\
\text { grades }\end{array}$ & $\begin{array}{l}\text { Grade } \\
3\end{array}$ & $\begin{array}{l}\text { Grade } \\
4\end{array}$ \\
\hline & $N(\%)$ & $N(\%)$ & $N(\%)$ & $N(\%)$ & $N(\%)$ & $N(\%)$ & $N(\%)$ & $N(\%)$ & $N(\%)$ \\
\hline \multicolumn{10}{|l|}{ Hematologic AEs } \\
\hline Neutropenia & $1(1.6)$ & & & & & & & & \\
\hline \multicolumn{10}{|l|}{ Anemia } \\
\hline Thrombocytopenia & $3(4.8)$ & $\begin{array}{l}2 \\
(3.2)\end{array}$ & $\begin{array}{l}1 \\
(1.6)\end{array}$ & $2(6.3)$ & $\begin{array}{l}1 \\
(3.1)\end{array}$ & & & & \\
\hline \multicolumn{10}{|l|}{$\begin{array}{l}\text { Non-hematologic } \\
\text { AEs }\end{array}$} \\
\hline Asthenia & $5(7.9)$ & $\begin{array}{l}1 \\
(1.6)\end{array}$ & & & & & $1(3.2)$ & $\begin{array}{l}1 \\
(3.2)\end{array}$ & \\
\hline Anorexia & $2(3.2)$ & & & & & & & & \\
\hline Nausea & $\begin{array}{l}7 \\
(11.1)\end{array}$ & $\begin{array}{l}2 \\
(3.2)\end{array}$ & & $1(3.1)$ & & & & & \\
\hline Vomiting & $5(7.9)$ & $\begin{array}{l}2 \\
(3.2)\end{array}$ & & $1(3.1)$ & & & & & \\
\hline Dizziness & $2(3.2)$ & & & & & & & & \\
\hline Stomatitis & $2(3.2)$ & & & $2(6.3)$ & & & & & \\
\hline Diarrhea & $3(4.8)$ & & & & & & $1(3.2)$ & & \\
\hline $\begin{array}{l}\text { Hand-foot } \\
\text { syndrome }\end{array}$ & $5(7.9)$ & $\begin{array}{l}1 \\
(1.6)\end{array}$ & & $\begin{array}{l}8 \\
(25.0)\end{array}$ & $\begin{array}{l}4 \\
(12.5)\end{array}$ & & & & \\
\hline Skin rash & $2(3.2)$ & & & & & & & & \\
\hline Neuropathy & $\begin{array}{l}19 \\
(30.2)\end{array}$ & $\begin{array}{l}5 \\
(7.9)\end{array}$ & & $1(3.1)$ & & & & & \\
\hline Peripheral edema & & & & $1(3.1)$ & & & & & \\
\hline Liver dysfunction & & & & $1(3.1)$ & $\begin{array}{l}1 \\
(3.1)\end{array}$ & & & & \\
\hline \multicolumn{10}{|l|}{ Renal dysfunction } \\
\hline AEs Adverse events & & & & & & & & & \\
\hline
\end{tabular}

\section{Survival Analysis}


Maintenance treatment was the only significant factor associated with PFS in univariate analysis (HR: 0.486 (95\% confidence interval [Cl]: 0.277-0.852)). Sex, disease status, and measurable lesion were not statistically significant factors in multivariate analysis (HR: 1.264, 95\% Cl: 0.718-2.226; HR: 0.614, 95\% Cl: 0.317-1.190; and HR: $1.468,95 \% \mathrm{Cl}: 0.788-2.735$, respectively). Maintenance treatment was the only significant factor in multivariate analysis (HR: $0.472,95 \% \mathrm{Cl}: 0.250-0.890, P=0.020$ ) (Table 3). 
Table 3

Univariate and multivariate analyses of progression free survival

\begin{tabular}{|c|c|c|c|c|}
\hline & $\begin{array}{l}\text { Hazard ratio on univariate } \\
\text { analysis }(95 \% \mathrm{Cl})\end{array}$ & $\begin{array}{l}P \\
\text { value }\end{array}$ & $\begin{array}{l}\text { Hazard ratio on } \\
\text { multivariate analysis }(95 \% \\
\mathrm{Cl})\end{array}$ & $\begin{array}{l}P \\
\text { value }\end{array}$ \\
\hline Age & & 0.650 & & \\
\hline$<60$ & 1.000 & & & \\
\hline$\geq 60$ & $1.135(0.657-1.962)$ & & & \\
\hline Sex & & 0.864 & & 0.417 \\
\hline Female & 1.000 & & 1.000 & \\
\hline Male & $0.972(0.705-1.341)$ & & $1.264(0.718-2.226)$ & \\
\hline Disease status & & 0.174 & & 0.148 \\
\hline Initial metastasis & 1.000 & & 1.000 & \\
\hline Recurrence & $0.667(0.372-1.195)$ & & $0.614(0.317-1.190)$ & \\
\hline $\begin{array}{l}\text { Previous adjuvant } \\
\text { chemotherapy }\end{array}$ & & 0.658 & & \\
\hline No & 1.000 & & & \\
\hline Yes & $1.152(0.617-2.151)$ & & & \\
\hline Clinical T stage & & 0.831 & & \\
\hline $\mathrm{T} 1,2$ & 1.000 & & & \\
\hline T 3,4 & $1.118(0.401-3.119)$ & & & \\
\hline Clinical N stage & & 0.809 & & \\
\hline No & 1.000 & & & \\
\hline$N 1,2,3$ & $1.136(0.405-3.188)$ & & & \\
\hline Number of metastases & & 0.990 & & \\
\hline 1 & 1.000 & & & \\
\hline$\geq 2$ & $1.003(0.579-1.738)$ & & & \\
\hline Liver metastasis & & 0.342 & & \\
\hline No & 1.000 & & & \\
\hline Yes & $1.357(0.723-2.546)$ & & & \\
\hline Peritoneal metastasis & & 0.401 & & \\
\hline
\end{tabular}




\begin{tabular}{|c|c|c|c|c|}
\hline & $\begin{array}{l}\text { Hazard ratio on univariate } \\
\text { analysis }(95 \% \mathrm{Cl})\end{array}$ & $\begin{array}{l}P \\
\text { value }\end{array}$ & $\begin{array}{l}\text { Hazard ratio on } \\
\text { multivariate analysis ( } 95 \% \\
\text { Cl) }\end{array}$ & $\begin{array}{l}P \\
\text { value }\end{array}$ \\
\hline No & 1.000 & & & \\
\hline Yes & $0.791(0.457-1.368)$ & & & \\
\hline Lung metastasis & & 0.611 & & \\
\hline No & 1.000 & & & \\
\hline Yes & $1.231(0.553-2.737)$ & & & \\
\hline $\begin{array}{l}\text { Nonregional lymph node } \\
\text { metastasis }\end{array}$ & & 0.581 & & \\
\hline No & 1.000 & & & \\
\hline Yes & $1.182(0.653-2.138)$ & & & \\
\hline Bone metastasis & & 0.695 & & \\
\hline No & 1.000 & & & \\
\hline Yes & $0.853(0.384-1.893)$ & & & \\
\hline Measurable lesion & & 0.454 & & 0.226 \\
\hline No & 1.000 & & 1.000 & \\
\hline Yes & $1.226(0.720-2.088)$ & & $1.468(0.788-2.735)$ & \\
\hline Smoking history & & 0.668 & & \\
\hline Never or Ex-smoker & 1.000 & & & \\
\hline Current smoker & $1.367(0.328-5.698)$ & & & \\
\hline $\begin{array}{l}\text { Previous response to } \\
\text { XELOX chemotherapy }\end{array}$ & & 0.830 & & \\
\hline Stable disease & 1.000 & & & \\
\hline $\begin{array}{l}\text { Partial response / } \\
\text { Complete response }\end{array}$ & $1.061(0.617-1.826)$ & & & \\
\hline Histology subtype & & 0.248 & & \\
\hline Well to moderate & 1.000 & & & \\
\hline Poor & $1.204(0.879-1.649)$ & & & \\
\hline Serum CEA (ng/ml) & & 0.754 & & \\
\hline$\leq 7.5$ & 1.000 & & & \\
\hline$>7.5$ & $0.930(0.590-1.466)$ & & & \\
\hline
\end{tabular}




\begin{tabular}{|lllll|}
\hline & $\begin{array}{l}\text { Hazard ratio on univariate } \\
\text { analysis }(95 \% \mathrm{Cl})\end{array}$ & $\begin{array}{l}\boldsymbol{P} \\
\text { value }\end{array}$ & $\begin{array}{l}\text { Hazard ratio on } \\
\text { multivariate analysis }(95 \% \\
\text { Cl) }\end{array}$ & $\begin{array}{l}\boldsymbol{P} \\
\text { value }\end{array}$ \\
\hline Maintenance treatment & & $\mathbf{0 . 0 1 2}$ & & $\mathbf{0 . 0 2 0}$ \\
\hline No & 1.000 & & 1.000 & \\
\hline Yes & $0.486(0.277-0.852)$ & & $0.472(0.250-0.890)$ \\
\hline CEA Carcinoembryonic antigen & & & \\
\hline
\end{tabular}

\section{Discussion}

Main findings of this population-based study are as follows. The primary endpoint of this study was met in that the capecitabine maintenance group showed significantly prolonged PFS than the observation group, although these two groups did not show statistically different OS. In maintenance group, most toxicities were manageable. There was no interruption of capecitabine maintenance due to side effects. Maintenance treatment was the only significant factor associated with PFS in both univariate and multivariate analyses.

Maintenance fluoropyrimidine therapy has been used for advanced CRCs. The OPTIMOX2 study [10] has showed that there was significant difference of duration of disease control between $5 \mathrm{FU} / \mathrm{LV}$ maintenance group and chemotherapy-free interval group (13.1 months vs 9.2 months, $P=0.046)$. This study provided us an important clue that maintenance treatment could be one of effective strategies to relieve neuropathy induced by cumulative effect of oxaliplatin.

In a phase II study published in 2011 [11], they evaluated the efficacy and safety of short-course capecitabine plus oxaliplatin followed by maintenance capecitabine in advanced CRCs. In 34 patients who was allocated to capecitabine maintenance group, the median PFS and OS was 8.1 months and 23.1 months, respectively. Although it was not a randomized clinical trial, OS more than 20 months is much longer compared to the survival of previous studies.

The initial support for maintenance regimen in the advanced GC comes from observational and retrospective studies, which show that maintenance fluoropyrimidine treatment might improve PFS than observation alone [12]. Petrioli et al. [13] studied maintenance chemotherapy with leucovorin/bolus and continuous infusion 5FU after administration of the FOLFOX-4 regimen in advanced esophagogastric cancer patients aged 75 years or older with impaired performance status. The result showed modest efficacy and tolerable toxicity of maintenance therapy.

Park et al. [14] have reported a randomized phase II study of continuous versus stop-and-go S-1 plus oxaliplatin following disease stabilization in first-line chemotherapy for patients with metastatic GC. Continuing chemotherapy showed PFS benefit in reducing risk of progression or death by $45 \%$ compared to stop-and-go strategy, and increased median PFS by 3.3 months. (10.5 months versus 7.2 months; HR: 0.55 , $95 \% \mathrm{Cl}: 0.37-0.81 ; P=0.002)$. However, this PFS gain was not related to the duration of disease control (DDC) or OS. So the authors insisted that continuous maintenance with the same doublet regimen in unselected metastatic GC patients is not recommended. 
For the study of molecular target agent, the phase 3 study [15] was performed to assess the efficacy of adding bevacizumab to capecitabine-cisplatin in the 1 st line chemotherapy of advanced GC. The study did not meet the primary endpoint, which was OS. For immunotherapy, Moelhler et al. [16] have reported results from a phase III trial of Avelumab maintenance after first-line induction chemotherapy versus continuation of chemotherapy in patients with GCs. Patients without progressive disease after 12 weeks of first-line chemotherapy with oxaliplatin plus a fluoropyrimidine were randomly assigned to avelumab switching maintenance or continuation of 1st line chemotherapy. There was no significant difference of OS with avelumab maintenance versus continued chemotherapy in patients with advanced GC overall or in a prespecified PD-L1-positive population.

So far, proven efficacy have not been found with several maintenance treatments for GC, although there have been positive results for capecitabine maintenance treatment in several retrospective or phase 2 trials. Capecitabine is used in the treatment of 1 st line chemotherapy and it has the advantage of safety and ease of administration [5].

The multicenter, phase II prospective study [17] was performed to find the efficacy and toxicity of paclitaxel plus capecitabine as first-line chemotherapy in advanced GC. After maximum of six cycles of the combination chemotherapy, the patients without disease progression received maintenance capecitabine. The survival of this maintenance group was 531 days, indicating that maintenance could benefit.

Multicenter, open-label phase II trial [18] was conducted in China to compare the efficacy and safety of capecitabine as maintenance treatment after $1 \mathrm{st}$ line chemotherapy for patients with advanced esophagogastric junction adenocarcinoma. When initial disease was controlled after capecitabine-based firstline combination chemotherapy, 60 patients were randomly assigned to receive a capecitabine treatment (oral capecitabine $1,250 \mathrm{mg} / \mathrm{m} 2$ twice daily on days 1-14 every 3 weeks) or not. Compared to controls, patients who received capecitabine maintenance therapy showed significantly prolonged PFS and OS (PFS median: 11 vs. 7 months, OS median: 17 vs. 11 months). There were no significant differences in the prevalence of adverse events between patients who received maintenance therapy and controls.

From 2008 to 2009, prospective observational study [6] was performed to determine the role of capecitabine maintenance treatment after first-line chemotherapy in advanced GC patients. The patients with grade 2 or higher neuropathy were enrolled after 6 cycles of oxaliplatin and capecitabine chemotherapy without disease progression. There was significant difference of median PFS between maintenance group and observation group (11.4 vs. 7.1 months, $P<0.001)$. In the multivariate analysis, the status of maintenance treatment was an independent prognostic factors as well as type of metastasis and the response to chemotherapy. Maintenance treatment showed a mild hematologic toxicities and manageable non-hematologic toxicities.

The hypothesis of our study was that PFS might be prolonged by continually exposing patients to chemotherapeutical agent compared with fixed cycles of XELOX. We selected PFS as the primary endpoint. Meta-analysis of randomized trials shows that improvements in PFS in advanced GC were closely associated with improvements in OS [19]. PFS has been used as a surrogate endpoint in many randomized clinical trials evaluating 1 st line chemotherapy of metastatic GC. 
Comparing previous studies for capecitabine maintenance treatment, the distinctive feature of our study was that this was the first randomized controlled phase III trial. This study compared the efficacy and toxicity between capecitabine maintenance and observation after 6 cycles of 1 st line XELOX chemotherapy for HER2 negative AGC. Although the study sample size was small, and the number of study subjects planned by the protocol was not met due to delayed patient registration, we found that PFS of the maintenance group was statistically longer than that of the observation group. Considering that there were more patients with poor differentiation of tissue in the maintenance group, the gain of PFS in the maintenance group was meaningful.

The maintenance treatment showed some side effects such as hand-foot syndrome. All toxicities in the study group were manageable. Capecitabine was administered with a slight dose reduction in the maintenance group, given that the median RDI was 0.9. However, there was no statistical difference in oS between the study group and the control group.

A number of studies evaluating the efficacy and side effects of maintenance treatment in HER2-negative advanced GC are currently underway. The Maintenance Teysuno® (S-1) in esophagogastric cancer (MATEO) trial is an ongoing multinational, randomized phase II study that explores the role of S-1 maintenance therapy [20]. After a 12 week first line platinum-fluoropyrimidine-based chemotherapy, patients without tumor progression are planned to be randomized in a 2:1 allocation to receive S-1 alone or continue with the same regimen as used during the primary period. In the future, results of ongoing randomized trial could be used to establish maintenance chemotherapy of AGC.

In conclusion, this phase III trial demonstrated that maintenance capecitabine could significantly prolong PFS. Considering its effect and acceptable toxicity, maintenance capecitabine could be a reasonable option after stabilization following six cycles of XELOX.

\section{Declarations}

\section{Acknowledgements}

The authors thank all patients and investigators who participated in this study. We also thank Roche Ltd. (Korea) for supplying capecitabine.

\section{Author Contributions}

Lee GJ, An HJ, Ko YH, Roh SY and Shim BY were involved in the study concept and design. All authors collected the data and contributed interpretation of data. Lee GJ, Kim HH and An HJ, Shim BY performed the analysis and Shim BY was involved in obtaining funding. Lee GJ, Kim HH and Shim BY wrote the paper.

\section{Funding}

This study was partly supported by Roche Ltd. (Korea). This was an investigator-initiated trial. The company was not involved in the interpretation of data, the preparation, review, or approval of the manuscript, or the decision to submit this study for publication. The corresponding author has full authority over this research data. The corresponding author is responsible for the final decision to submit this study for publication. 


\section{Conflict of interest}

The authors have no conflicts of interest relevant to this study to disclose.

\section{Ethical approval}

All procedures performed in studies involving human participants were conducted in accordance with the ethical standards of the institutional and/or national research committee and with the 1964 Helsinki declaration and its later amendments or comparable ethical standards. The Institutional Review Board of the Catholic Medical Center approved this study (number: XC14MIMS0024H). Study subjects provided their informed consent to participate the study,

\section{Informed consent}

Objectives and potential risks and benefits were explained to patients using the informed consent form approved by the Institutional Review Board, with each patient having signed and dated toe form before screening.

\section{References}

1. Faivre J, Forman D, Esteve $\mathrm{J}$ et al (1998) Survival of patients with oesophageal and GCs in Europe. EUROCARE Working Group. Eur J Cancer 34:2167-2175

2. Siegel RL, Miller KD, Jemal A (2015) Cancer statistics, 2015. CA Cancer J Clin 65:5-29

3. Muro K, Van Cutsem E, Narita Y et al (2019) Pan-Asian adapted ESMO clinical practice guidelines for the management of patients with metastatic GC: a JSMO-ESMO initiative endorsed by CSCO, KSMO, MOS, SSO and TOS. Ann Oncol 30:19-33

4. Catalano V, Graziano F, Santini D et al (2008) Second-line chemotherapy for patients with advanced GC: who may benefit? $\mathrm{Br} \mathrm{J}$ Cancer 99:1402-1407

5. Eren OO, Ozturk MA, Sonmez OU et al (2016) Safety, feasibility, and efficacy of capecitabine maintenance in patients with advanced GC: a retrospective study. Am J Ther 23:e1493-e1497

6. Qiu MZ, Wei XL, Zhang DS et al (2014) Efficacy and safety of capecitabine as maintenance treatment after first-line chemotherapy using oxaliplatin and capecitabine in advanced gastric adenocarcinoma patients: a prospective observation. Tumour Biol 35:4369-4375

7. Yao Y, Deng R, Liao D et al (2020) Maintenance treatment in advanced HER2-negative GC. Clin Transl Oncol 22:2206-2212

8. Japanese GC A (2021) Japanese GC treatment guidelines 2018 (5th edition). GC 24:1-21

9. Park YH, Lee JL, Ryoo BY et al (2008) Capecitabine in combination with Oxaliplatin (XELOX) as a first-line therapy for advanced GC. Cancer Chemother Pharmacol 61:623-629

10. Chibaudel B, Maindrault-Goebel F, Lledo G et al (2009) Can chemotherapy be discontinued in unresectable metastatic colorectal cancer? The GERCOR OPTIMOX2 Study. J Clin Oncol 27:5727-5733

11. Waddell T, Gollins S, Soe W et al (2011) Phase II study of short-course capecitabine plus oxaliplatin (XELOX) followed by maintenance capecitabine in advanced colorectal cancer: XelQuali study. Cancer 
Chemother Pharmacol 67:1111-1117

12. Roviello G, Rodriquenz MG, Aprile G et al (2021) Maintenance in GC: New life for an old issue? Crit Rev Oncol Hematol 160:103307

13. Petrioli R, Francini E, Roviello F et al (2015) Treatment of advanced oesophagoGC with FOLFOX-4 regimen followed by leucovorin/bolus and continuous infusion 5-FU as maintenance chemotherapy in patients aged $>/=75$ years with impaired performance status. J Geriatr Oncol 6:380-386

14. Park SR, Kim MJ, Nam BH et al (2017) A randomised phase Il study of continuous versus stop-and-go S-1 plus oxaliplatin following disease stabilisation in first-line chemotherapy in patients with metastatic GC. Eur J Cancer 83:32-42

15. Ohtsu A, Shah MA, Van Cutsem E et al (2011) Bevacizumab in combination with chemotherapy as firstline therapy in advanced GC: a randomized, double-blind, placebo-controlled phase III study. J Clin Oncol 29:3968-3976

16. Moehler M, Dvorkin M, Boku N et al (2021) Phase III trial of avelumab maintenance after first-line induction chemotherapy versus continuation of chemotherapy in patients with GCs: results from JAVELIN Gastric 100. J Clin Oncol 39:966-977

17. Gong J, Hu B, Zhang X et al (2014) The multicenter, phase II prospective study of paclitaxel plus capecitabine as first-line chemotherapy in advanced gastric carcinoma. Oncologist 19:173-174

18. Lu B, Bao LB, Sun Z et al (2015) Efficacy and safety of capecitabine as maintenance therapy after capecitabine-based combination chemotherapy for patients with advanced esophagogastric junction adenocarcinoma. Eur Rev Med Pharmacol Sci 19:3605-3612

19. Shitara K, Ikeda J, Yokota T et al (2012) Progression-free survival and time to progression as surrogate markers of OS in patients with advanced GC: analysis of 36 randomized trials. Invest New Drugs 30:1224-1231

20. Haag GM, Stocker G, Quidde J et al (2017) Randomized controlled trial of S-1 maintenance therapy in metastatic esophagoGC - the multinational MATEO study. BMC Cancer 17:509

\section{Figures}




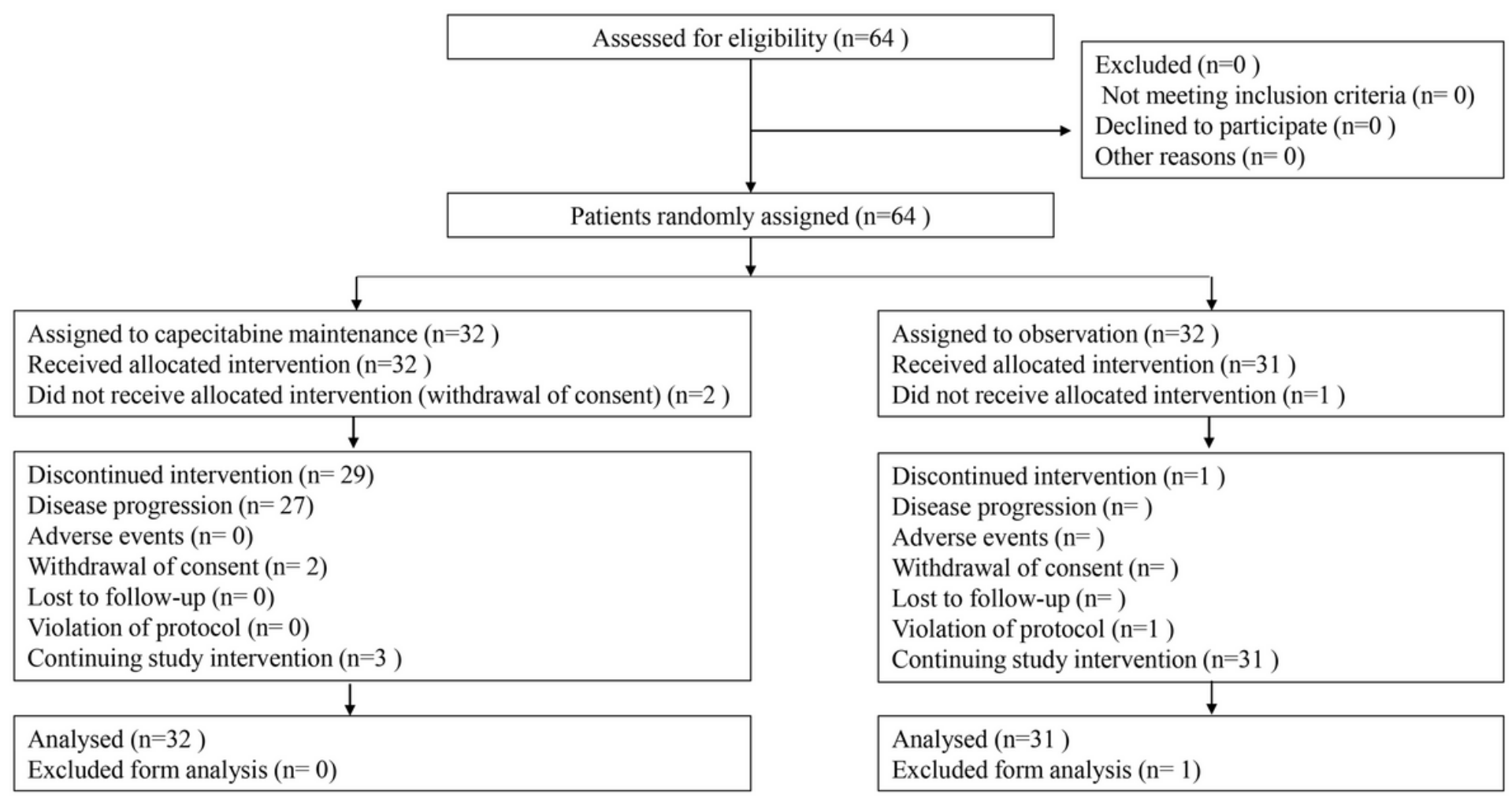

\section{Figure 1}

Study flow chart showing the selection of study subjects. 


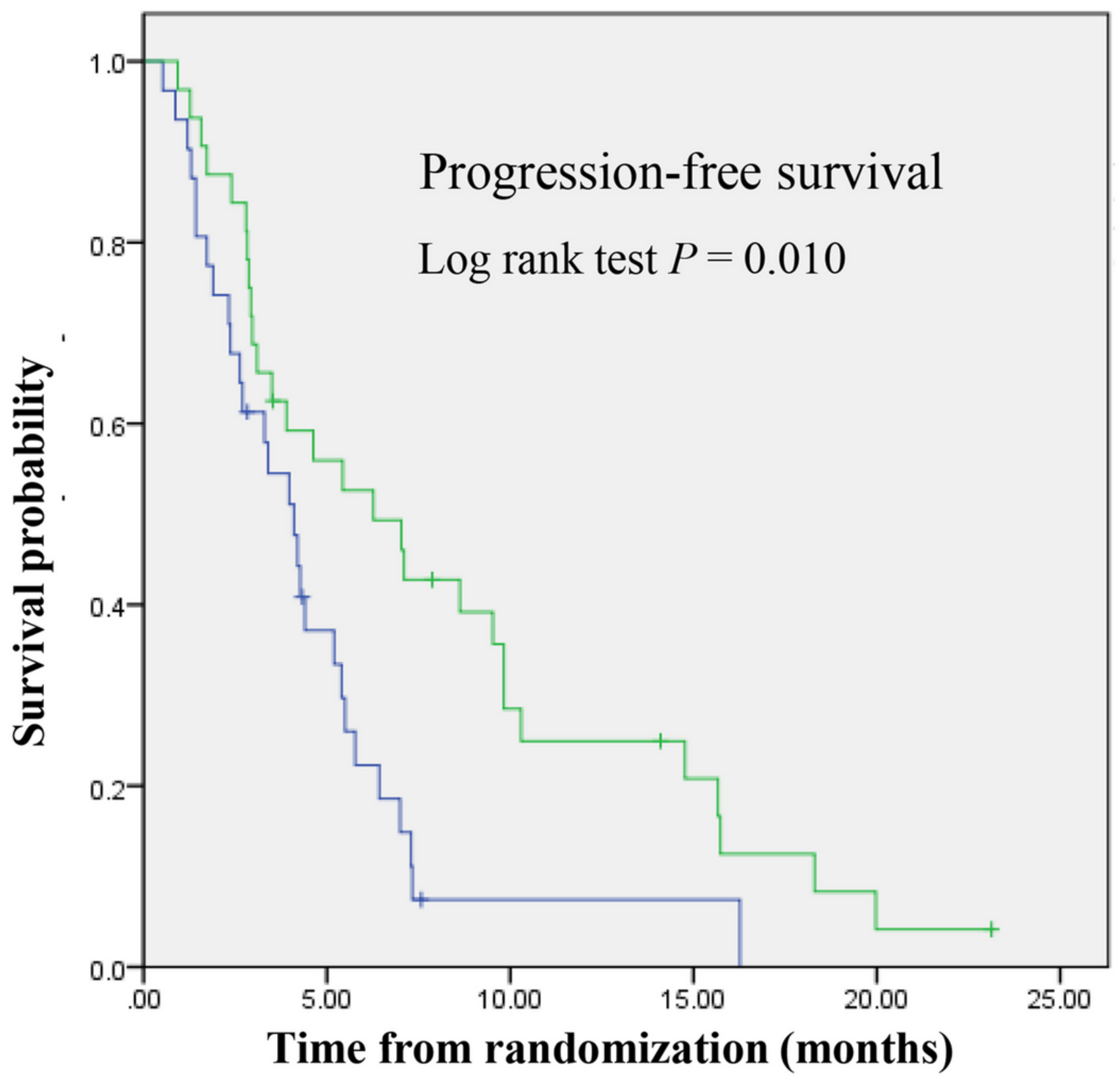

Maintenance group

Observation group

Figure 2

Kaplan-Meir analysis of PFS from randomization. 


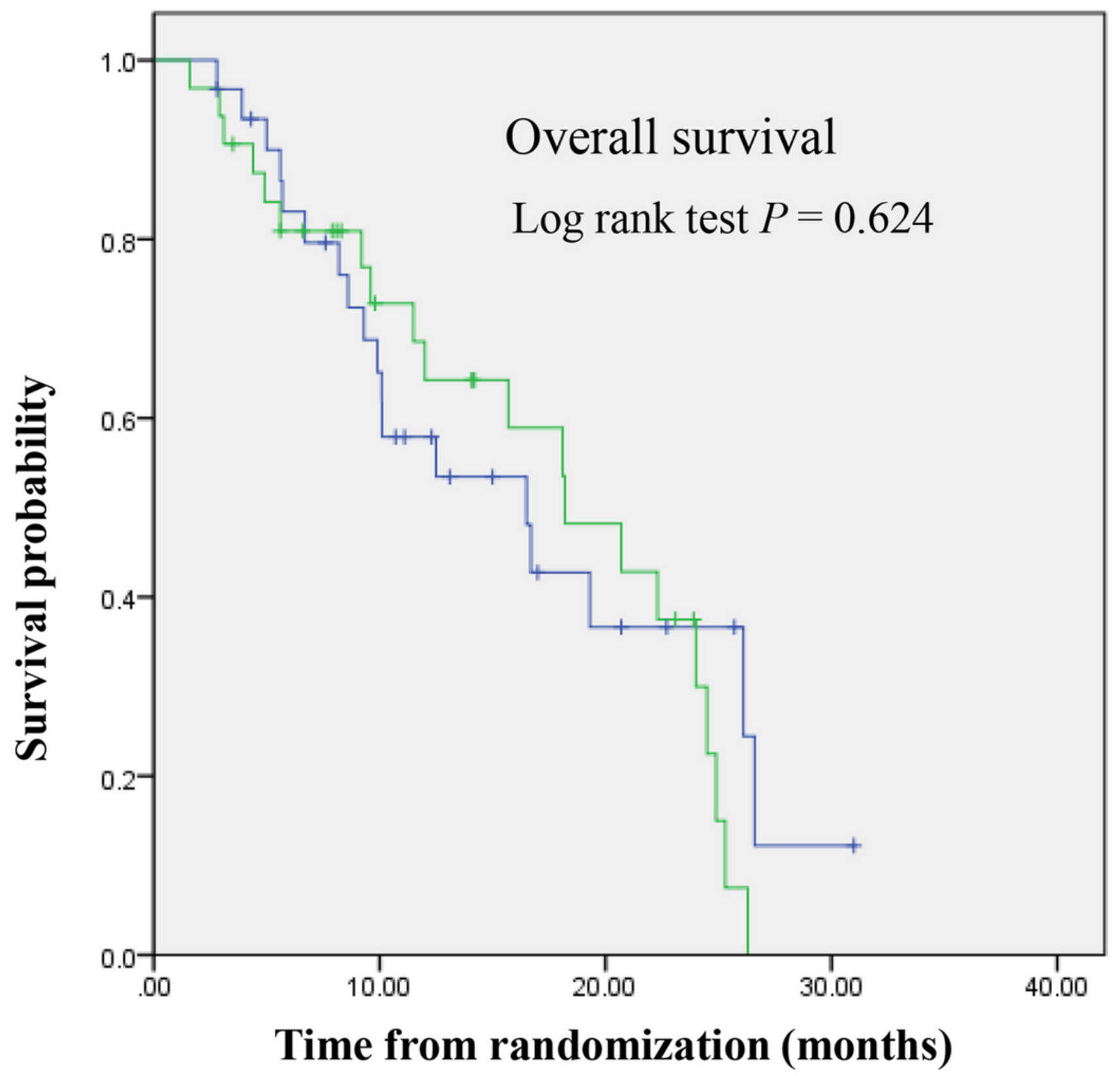

Figure 3

Kaplan-Meir analysis of OS from randomization. 